\title{
Flexible Irrigation Systems: Concept, Design, and Application
}

\author{
John L. Merriam, P.E.'; Stuart W. Styles, P.E.; and Beau J. Freeman ${ }^{3}$
}

\begin{abstract}
This paper presents the need, value, and concept of flexible irrigation water supply systems that can deliver water with flexibility in frequency, rate, and duration under the control of the farmer at the point of application using a limited rate arranged-demand or other schedule. It introduces the needed terminology including "congestion"-how much reserve time and capacity is required to assure water delivery at the frequency and rate desired. An illustrative design procedure for the necessary pipeline and reservoir capacities is illustrated. The techniques discussed emphasize the conversion of the economical steady supply canal flows to flexible on-farm usage through the use of service area reservoirs located between the secondary and tertiary systems, and of semiclosed pipelines and/or level-top canals as automated distribution systems which facilitates the farmers' need for daytime only variable on-farm deliveries to permit optimization of on-farm water management. This improved management is the ultimate source of increased food production after improved crop, land, and water resources have reached their maximum. The coordinated use of return flow systems is described.
\end{abstract}

\section{Introduction}

In areas where irrigation is essential for crop production, the effective and responsible management of water resources is critical. The on-farm problems created by the use of a rigid rotation schedule that permits a canal to operate continuously at a constant flow rate (an engineer's dream but a farmer's nightmare) are beginning to be acknowledged in planning. The rigid rotation supply forces wasteful water use such as improper timing, over irrigation and runoff, prevents effective use of rainfall, requires inconvenient and excessive labor, creates conflicts over water, and inhibits good farm management. It may be associated with subsurface drainage, high water table caused salinity, and reduced production problems.

A flexible irrigation supply permits a farmer to manage his land, water, weather, and labor resources as one integrated unit within his total farming program. Flexibility is essential to optimizing farming operations and maintaining sustainable irrigated agriculture. The value to widely utilized surface irrigation methods of large variable flow rates and daytime only sets, and half or less as much labor conveniently and more effectively used, must be considered in the economics of projects (Merriam and Freeman 2002).

${ }^{1}$ Professor Emeritus, BioResource and Agricultural Engineering Dept., California Polytechnic State Univ. (CalPoly), San Luis Obispo, CA 93407.

${ }^{2}$ Director, Irrigation Training and Research Center (ITRC), Cal Poly, San Luis Obispo, CA 93407. E-mail: sstyles@ calpoly.edu

${ }^{3}$ Senior Water Resources Engineer, ITRC, Cal Poly, San Luis Obispo, CA 93407. E-mail: bfreeman@calpoly.edu
The engineer often considers adequate scheduling as delivering water on the day the farmer needs it (or in a set rotation) with a volume as needed but with a fixed rate and duration such as $24 \mathrm{~h}$. These restraints have no correlation with soil intake rate or consideration of farmer labor or its convenience. The convenience of irrigating when and with the flow rate desired has value to a farmer and he is willing to pay a higher water charge for the improved service. "It is not just the volume of water delivered, but the way it is delivered to make it usable," that is important. "The engineer must learn to think like an educated farmer."

Educated on-farm control of irrigation water deliveries permits appreciable reduction in drainage and salinity problems caused by excess and nonuniform application (Styles 1997). A limited rate arranged-demand schedule (ASCE 1984) is the desired practical schedule. The farmer on an arranged day, and as desired (demand) can take a variable flow up to the system's design limit, use it as long as needed to infiltrate to the desired depth, and then shut off the irrigation when he is finished.

To obtain flexibility requires flow rate changes of appreciable magnitude. The lateral and distribution systems must be able to transmit variable flows. Daytime only irrigation at least doubles a continuous flow rate requirement and for eight hour days will need triple capacity. It will require no flow at night in the distribution system. Having the reserve capacity to permit choice of irrigation frequency at the lower end of a lateral may double lateral (but not distributor) capacity requirements again. However, only some of the farmers on a particular lateral will want to irrigate on any given day, so the averaging affect of many users may mean the upper portion of the system requires only a small increase in capacity. The flow if left in a main canal at night becomes the next day's supply further downstream, or it can be placed in a re-regulating reservoir system. Operational spillage may be practical where the spillage is reused.

The large capital-intensive main water supply system operates most effectively at or near capacity and continuously. The essential storage for fluctuating flows may be obtained from: (1) initial supply reservoirs; (2) in-canal storage; (3) in-the-canal reservoirs; 
(4) beside-the-canal reservoirs filled and/or emptied by pumping or gravity; (5) service area reservoirs close to the point of use which are emphasized in this paper for new or rehabilitated projects; and (6) of course by combinations supplemented by canal operations. The number and size of the farms, the desired duration and maximum flow rate, and the control of frequency of the delivery have impact on the size of the storage capacity needed, and great impact on the interconnecting conveyance and delivery capacity. Almost all distribution systems to fields or farms operate intermittently. At field levels the intervals typically create one to several weeks of non-use. To reconcile these extremes requires storage and scheduling. The most economical location for a large part of this storage is close to the point of distribution between the secondary and tertiary systems so that the capital-intensive continuous use area is above this point.

The essence of the concept of a flexible water supply is to provide the farmer with management control of the frequency, rate and duration of irrigation water delivery. He can then effectively manage the entire farm program as a unit without restraints created by the usual water supply system. It is important to realize that this management capability is the potential source of the ultimate increment of food production after the land and water resources and crop improvement have reached their limit. It permits a good farmer to become an excellent farmer.

\section{Terminology}

A new essentially replacement terminology is needed for flexible irrigation systems. Its consistent use will assist in comprehension by farmers, engineers, irrigation professionals, financiers, and project planners. The term watercourse is widely used to describe ditches. Earth ditches often present maintenance problems of weeds and silt, have seepage losses, are not easily crossed over, are restricted as to location, and cannot be farmed. The term watercourse must not be used in flexible irrigation supply vocabulary. It will be replaced by farm distribution pipeline or distributor (tertiary) on which the farm outlets are placed within pipeline distribution areas. The great difference in the capabilities of ditches and pipelines as to right-of-way, maintenance procedures, and delivery capability (upstream versus downstream control) prevent interchangeable use. Though their location and basic objectives are similar, their utilization is not. Ditches are not capable of truly flexible operation.

A lateral (secondary) system will supply the distribution area. It consists of a lateral or conveyance pipeline and/or a level-top canal operating under downstream control in response to farm demands. The pipelines will almost invariably and economically be low pressure semiclosed pipelines with the many advantages of pipelines over ditches (Van Bentum and Smout 1994; Merriam 1987a,b). A level-top canal essentially acts as a an extension of a reservoir but at a constant lower level maintained by a Neyrtec or Waterman float controlled gate regardless of the flow rate (Goussard 1987).

To automate the pipelines, (Merriam 1987a) semiclosed, Harris float valve controlled pipelines are nearly essential (Merriam 1987b). By responding to downstream variable demands the float valves provide a stable minimum and maximum low pressure in the lines for engineering purposes and importantly, they also provide a stable pressure and flow rate at the farm turnout as lateral and distributor flow rates are changed. A closed pipeline cannot do this.

Branch or main pipelines or canals (primary), or a reservoir will supply the laterals. They can be upstream or downstream controlled.

In most cases, the main and branch canals will receive water from rivers or primary reservoirs at fairly stable rates and operate with manual controls or under some degree of automatic upstream or downstream control as is prevalent on most current projects. The flexible supply system design provides a way to convert the fairly steady canal flows to the farmer-needed variable flows. They may become a no-flow condition at night. The economical balance of costs between canal sizing, in-canal storage, canal operation, and the essential reservoir capacity for night and operational storage for the delivery system, will almost always involve a service area reservoir.

Conceptually, a service area is a group of farms on a lateral supplied at one point from a main or branch. Below this point automation is essential to provide a flexible supply. However, at this point manual canal turnout controls are practical with a planned operation program using the service area reservoir to convert steady canal and turnout flows into variable flows at the farm. The service area reservoir for daytime operation (10-14 h) is most effectively located near but above the center of the service area, although it may be at the canal turnout. The area needed is seldom as much as $1 \%$ of the service area. If all the withdrawals were to be within eight hour periods, two reservoirs at about third points storing for about sixteen hours would be practical.

The design of a flexible supply system is facilitated by the use of the terms: Irrigated farm (or field), unit farm area, and unit farm stream. The irrigated farm is the unit farm (or field) that will be irrigated on the arranged day. Importantly, it requires an arranged day regardless of size.

The unit farm (or field) area is the selected representative-fordesign numerical area that can be irrigated in one day (10-14 h) by an irrigator having a large, flexible unit farm stream and good equipment. In locations with small land holdings, its size is selected in the upper range of ownership sizes, often at about $1-3$ ha $(3-8$ acre). The size can be varied in different parts of large projects. In the United States, unit farm sizes may be 4,8 , or even 16 ha $(10,20$, or even 40 acre).

The unit farm stream is selected as the probable near maximum (not average) stream size needed to apply an irrigation using good equipment in one or more sets in the daytime (ten to fourteen hours) to a unit farm area at good efficiency $(75 \% \pm)$. Usually this concerns the large initial stream for a furrow irrigated field which is cutback. Startup times for irrigated farms can be staggered by arrangement. Furrow advance ratios (AR) (time of advance/time of infiltration at the lower end) should be between 0.5 and 1.0 for good distribution uniformity (DU) (Merriam 1988). Border-strip and basins easily conform (Merriam 1978; Merriam and Clemmens 1985). This unit farm stream size must be carefully selected based on evaluation (if possible) of actual field conditions and soil infiltration range of values. It must be done with consideration of present and future conditions and methods. Its size affects application efficiency and hours spent irrigating (a farmer cost) and capital investment as to pipe capacities needed (a project cost). "The farm and the project are one financial unit."

Congestion is the fundamental expression of how flexible a system is - how much reserve capacity does it have available for management, how much of the time is it in use, how is planning and neighbor use restricted? It is the percent ratio of the number of days a line would need to cover an area with one or several streams continuously used, to the number of days planned for use (e.g., the number of days needed to the number of days available 
Table 1. Practical Congestion Ranges (\%)

\begin{tabular}{llllr}
\hline Distributor & $\begin{array}{l}\text { Lower } \\
\text { lateral }\end{array}$ & $\begin{array}{l}\text { Upper } \\
\text { literal }\end{array}$ & Branch & Main \\
\hline $50-60$ & $60-70$ & $65-80$ & $70-85$ & 85 \\
\hline
\end{tabular}

to cover an area at peak demand). For this presentation based on experience that farmers do not often willingly and effectively irrigate at night, capacities are based on daytime only use, though some night use may actually be arranged

Congestion $(\%)$

$$
\begin{aligned}
& =\frac{\text { number of irrigated farms } \times \text { number of irrigation days per farm }}{\text { number unit streams } \times \text { irrigation cycle days }} \\
& \times 100
\end{aligned}
$$

For example, if there were ten irrigated farms each requiring one day (daytime only) to irrigate on a distributor of one stream capacity, and the cycles (frequency) were ten days, the congestion would be $100 \%$, used every day and no reserve (except at night).

If two streams were available, it could be used only $50 \%$ of the time, lots of reserve capacity. This flexibility might be obtained by converting from using only $200 \mathrm{~mm}$ (8 in.) (one stream) diameter pipe for the whole length, to using $250 \mathrm{~mm}$ (10 in.) (two stream) diameter for the upper half and $200 \mathrm{~mm}$ (8 in.) for the lower half. The increase in the distribution pipeline cost would only be about $7 \%$ for double the capacity.

Acceptable Congestion is a variable. It is a matter of judgment within an acceptable range. If the distributors have a lower congestion and there is lots of reserve time, the laterals can have a little more congestion. The total number of irrigated farms, not the area, requiring a day of use, enters into the consideration. A whole pipeline distribution area in a developing country having ten farms requiring two streams for $50 \%$ congestion, may be only one field in the United States utilizing a large unit farm stream for only one day.

The larger the number of farms on a distributor, or pipeline distributors on a lateral, or laterals on a branch or main canal, the more nearly the operation will approach an average use rate. Congestion can be increased with more intensive use, but reserve for unusual weather or other conditions must be retained. Consideration may be given to variations in cropping pattern and amount of land fallow at peak periods over the life of the project. "Do not limit the future by what is built now."

Table 1 presents congestion values based on personal experience. Local experience to refine these values should be developed.

\section{Illustrative Design}

The following design procedure illustrates the concepts of flexibility based on an operation plan utilizing a limited rate arranged-demand schedule though it may be less effectively used with other schedules. Use of a limited rate arranged-demand schedule requires the farmer to apply in advance to arrange for a day upon which he is permitted the use of the system. An assured minimum and a maximum rate (limit) are set in the design procedure by the pipeline or turnout capacity. The farmer's actual rate is seldom the maximum rate. The requirement of scheduling arranged days prevents overloading. A reasonable congestion limit provides assurance of availability under most conditions. Implicit in this design procedure is that usually the farm will be irrigated only during the daytime. This condition is a very high priority among the educated (experienced) farmers using a flexible supply system. During the arranged day, the irrigator can take water as he wishes as to rate and duration (demand) up to the system limiting rate, and at night if so arranged if the system supply volume is adequate.

In the design procedure a base map is needed at a workable scale showing topography, ownership or subdivision boundaries, and a soil survey map (a GIS one is helpful). A tentative irrigation layout of distributors, laterals, branches (and main) is superimposed. Under some conditions, it may be reasonable to modify field boundaries to facilitate irrigation methods. For example, prior to designing the irrigation layout, the top and bottom property lines can be relocated if necessary to make them parallel or to approximate a contour so reasonable cross slope irrigation grades will not leave odd shaped pieces of land. In addition, long, narrow repeatedly subdivided fields (by inheritance) can be consolidated into shorter wider units with farmer concurrence.

The unit farm area value is selected with consideration of present and future actual farm boundaries. It is usually a bit larger than a majority of nearly all of the farms or fields presently used. If an actual ownership is much larger, two days and possibly two outlets can be arranged and considered when reviewing the congestion. Two small areas needing small streams, after consultation with the owners, could be allocated half days or half streams if soils and methods permitted. There is considerable leeway and judgment at this point in selecting the pipeline distribution areas and in laying out the distributor and lateral pipelines related to the actual farm boundaries. Pipelines provide much more freedom as to location than do ditches. They can go across fields and up and down. Structures should be placed at field edges.

The size of the unit farm stream is not pertinent at this stage. The procedure is to select the number of streams (congestion and days of use) needed at various locations which can later be converted to flow rates and pipe sizes. Pipeline distribution areas should be small enough to require only one or two unit farm streams. More than three is undesirable as it creates more flow variation, and difficulty in metering if that is desired.

For farmer utilization of upgraded irrigation systems and methods, some simple mathematical processes are convenient for management and also for design. Evapotranspiration of a crop is given in $\mathrm{mm} /$ day (or in./day), rainfall is $\mathrm{mm} /$ day (or in./day), soil moisture deficiency in the root zone depth is in $\mathrm{mm}$ (or in.). Ordered or applied water needs to be convertible into comparable depth units. In the British system a flow rate of $1.0 \mathrm{cfs}$ for $1.0 \mathrm{~h}$ applies 1.0 in. on 1.0 acre (a cfs h equals an ac in.). A comparable metric flow unit applying $1.0 \mathrm{~cm}$ on $1.0 \mathrm{ha}$ in $1.0 \mathrm{~h}$ is one basic stream, which is $100 \mathrm{~m}^{3} / \mathrm{h}$ or $27.78 \mathrm{lps}(0.98 \mathrm{cfs})$ [ 1.0 basic stream hour equals $1.0 \mathrm{hacm}$. This is a very practical sized stream, and easily visualized by an irrigator. Its use rather than "lps" is easier and facilitates upgraded management. It is far easier for a farmer to compute the need and arrange for $1,11 / 2$, or 2 streams rather than to request 28, 37, or $56 \mathrm{lps}$.

For design purposes, the selected irrigation cycle length (interval) is related to crop, climate, soil variations and management allowable deficiency (MAD) (Merriam 1966). Moderate variations in the design cycle length with an acceptable effect upon congestion are of little consequence. The magnitude of the irrigation cycle must be representative of the actual conditions under peak use plus a little reserve. Its precise value is not important, but a design value must be selected. It is a key value in considering congestion and it must be a practical whole number. It is similar to rotation cycles which are often 7,10 , or 14 days for 
Table 2. Number of Streams and Congestion for Illustrative Lateral 10-day Cycle, 10 Distributions, 120 Farms

\begin{tabular}{|c|c|c|c|c|c|c|c|c|c|c|}
\hline Distributor no. & 1 & 2 & 3 & 4 & 5 & 6 & 7 & 8 & 9 & 10 \\
\hline Number of farms & 10 & 14 & 6 & 16 & 5 & 12 & 18 & 11 & 15 & 13 \\
\hline Number of streams & 2 & 2 & 1 & 3 & 1 & 2 & 3 & 2 & 3 & 2 \\
\hline Distributor congestion $\%$ & 50 & 70 & 60 & 53 & 50 & 60 & 60 & 55 & 50 & 65 \\
\hline Totalized No. of farms & 10 & 24 & 30 & 46 & 51 & 63 & 81 & 92 & 107 & 120 \\
\hline Totalized No. of streams & 2 & 4 & 5 & 8 & 9 & 11 & 14 & 16 & 19 & 21 \\
\hline Reduction $\%$ & 0 & 0 & 5 & 5 & 10 & 10 & 15 & 15 & 20 & 25 \\
\hline Adjusted No. of streams & 2 & 4 & 5 & 7 & 8 & 10 & 12 & 14 & 15 & 16 \\
\hline Lateral congestion $\%$ & 50 & 60 & 60 & 66 & 64 & 63 & 67 & 66 & 71 & 75 \\
\hline
\end{tabular}

Note: Each farm requiring one irrigation day with one stream.

farmer rotation convenience, but the design cycle is not so impacted. It is the increment of days in which a distribution area or a service area needs to be covered with a continuously (daytime only) flowing supply of planned size.

Using the map, note at each distributor turnout from the lateral the required number of streams needed for the distributor for acceptable distribution congestion, typically 1 or 2 , seldom 3 . Moving up the lateral, the cumulative number of streams should be noted for each lateral reach. These items can be tabulated along with other helpful information. This is illustrated in Table 2 for a 10-day irrigation cycle and 10 distributors on a lateral for farms requiring one day of irrigation with one stream each. It illustrates an arbitrary percent reduction related to probability to decrease the number of streams on the lateral to conform to an acceptable congestion value (see Table 1).

A presentation of design scheduling impact is presented by Clemmens (1987) but for $24 \mathrm{~h}$ durations rather than daytime only (12 h).

The use of the arbitrary reduction percent procedure selected to obtain a chosen congestion at the inlet and starting with zero at the lower end, is a representation of probability. It is practical to assign reasonable congestion percents and work backwards to obtain the number of streams (whole numbers). It should be supplemented with site-affected judgment. At distributor 4, the number of streams was reduced from 8 to 7 even though the indicated arbitrary percent reduction of 5\% would not justify it. The rounded values of percent are intentionally shown to emphasize that theoretically refined precision is not justified when answers are in whole numbers, but judgment should be used. The important follow-up questions are; "What is the difference in the annual project cost per unit of water delivered to use a pipeline for 8 streams with a congestion of $58 \%$ over one conveying 7 for this reach at a congestion of $66 \%$ ?" and "Will this saving create practical problems?" The final congestion numbers imply reasonable reserve (see Table 1).

The next design step is to select the unit farm stream size. Its value is representative in a large area so it will not have an exact value, but it must be practical and fully adequate. Whether it is 100 or $110 \mathrm{lps}$ is not of concern. With a flexible schedule, adequate education and pipelines, the application efficiency can be at least $75 \%$. Select a stream size value using judgment. It must be adequate to supply the unit farm requirement $\left(\mathrm{MAD} / \mathrm{E}_{\mathrm{a}}\right)$ in one $12 \mathrm{~h}$ day, daytime only, while considering soil intake rate and initial stream options. Thinking like a farmer, select the largest one since it will save time and labor, and then thinking like a cost-minded engineer, select the smallest. As a design engineer select the economical one considering the farm and the project as one financial unit, and then make it a bit larger and round it off. "Do not limit the future by what is built now."
On the map for each reach, note the flow rate (number of streams $x$ unit stream flow rate). Then for the available gradient note a trial pipe size for each reach. Hydraulic design then follows with consideration of minimum head on farm turnouts, minor losses, Harris float valve losses (Merriam 1987b), needed pressure at the inlet, etc. (Van Bentum and Smout 1994). Designing flow to the far end of a reach provides conservative conditions. For distributors with two streams, the upper reach may be 0.6 to possibly 0.7 of the length. These conditions are site specific and the upper and larger portion should be made adequately long, not just halfway. Probability of where the two streams may simultaneously be used must be considered. For three streams more than thirds is reasonable. Make a synthetic operation plan to visualize onsite potentials. Arranged scheduling can control where and when on a line water is taken out. The engineer should think of the farmers as the clients to be satisfied and who generate the wealth to pay for the project. "The farm and the project are one financial unit."

The Harris float valves have two function in a semiclosed pipeline system. First is to break line pressure into steps in conformance with pipe and joint capabilities to resist pressure, usually about 5 to $6 \mathrm{~m}$. This will permit the use of lower cost low pressure pipe. Concrete $1.0 \mathrm{~m}$ length nonreinforced tongue and groove mortar joint irrigation class pipe (ASAE S261 1989) frequently proves to be the most economical with a maximum head of about $6 \mathrm{~m}$. Gravity farm turnout heads desirably are less than this.

In developing countries concrete usually does not require foreign exchange. It can often be made locally. The second function is pertinent to flexible system operation-maintain a stable flow condition at the farm turnout as flow conditions are changed in the pipeline system creating an unstable pressure condition. Many times the distributor can be stabilized from the float valve stand on the lateral, or alternately with a beside-the-line stand when lateral pressure variations are undesirably large.

As the several lateral lines join the branch (or main) (Table 1), the process is repeated with higher values of congestion as the additional farms tend to approach a more nearly average flow. In Table 2, a distributor having ten farms and two streams, would average one farm a day but could have two or zero on some days. A lateral with 120 farms and 16 streams averaging 12 farms a day may range for $8-16$, but seldom go to zero unless it rains and could be restricted to 16 maximum. The arranged schedule provides adequate restraint on the number of users and where.

A representative service area on most projects will range from perhaps 100 to a 1,000 ha (250-2,500 acre). A lateral pipeline would take off from a branch or main canal which flows continuously at a fairly stable average rate varied by seasons and schedules. The essential on-farm flexibility of rate and duration would 
be created by some canal operations but mostly by a service area reservoir. It would be located near the center of the service area. A bit above would be preferable, as it would more nearly equalize the daytime flow with its needed operational spillage with the night flows for the lower area.

If it were capable of storing just the overnight unused flow for the service area it impractically would be done only in conjunction with appreciable farmer restraints and canal operation. Better, a full day's storage would require only moderate canal coordination and would greatly reduce the need for precise canal operation permitting mismatches to be adjusted a day later and would cost only a little more. It probably would reduce new canal capital costs and certainly the operation costs and possibly adsorb operational spillage from the main canal. It could be compatible with simple manual canal operations to upgrade an old canal and generally would be the most practical size. An operation plan at peak conditions should be developed. The larger the reservoir, the simpler and less precise the operation becomes.

It may be practical to pump up into or from a reservoir to create the essential head on a pipeline system. Pumping is done for the Imperial Irrigation District interceptor systems and for almost all of Egyptian irrigation. Consideration must be given with a flexible supply system to the potential for rapid drawdown problems in canals and reservoirs.

\section{Comments on Capacities}

\section{Stream Sizes}

The design unit farm stream size (not the illustrated average) as well as the irrigation unit farm area must be carefully determined and be adequate for future conditions and any practical method. The decision on the size of the unit farm stream appreciably affects the cost of the distributor and the laterals, and less so on the branch canals or pipelines and negligibly so on the main canalthe same volume of water is delivered in a day. Changing pipe sizes from $200 \mathrm{~mm}$ to 250 and $300 \mathrm{~mm}$ (8 in. to 10 and $12 \mathrm{in}$.) increases the flow capacity by two and three times, respectively, however, costs increase only about $15 \%$ and $40 \%$ and project total costs perhaps only $2-5 \%$ with corresponding small increases in water rate charges. This increase in pipeline cost must be weighed against the major benefits the additional flow capacity will have on farm management, irrigation labor and efficiency. It is seldom truly economical to be very restrictive in this choice.

The desired delivery capability to provide an application of say $125-150 \mathrm{~mm}(5.0-6.0 \mathrm{in}$.) including losses, per work day is controlled by soil intake rate limitations and method. If a unit field for one irrigation set in the United States were about 8.0 ha (20 acre) for a $6.0 \mathrm{~h}$ furrow infiltration time and $4.0 \mathrm{~h}$ advance time resulting in a set time of $10.0 \mathrm{~h}$ applying $125 \mathrm{~mm}$ (5.0 in.), the flow average rate would be

$$
\begin{aligned}
0.125 \mathrm{~m} \times 8.0 \mathrm{ha} \times 10,000 / 10 \mathrm{~h} \\
=1000 \mathrm{~m}^{3} / \mathrm{h} \\
=280 \mathrm{lps}(10 \mathrm{cfs}) \text { per } 8.0 \mathrm{ha}(20 \text { acre }) \text { field }
\end{aligned}
$$

If basins were used, a larger flow rate of $1500 \mathrm{~m}^{3} / \mathrm{h}$ for $6.7 \mathrm{~h}$ might be desirable at the farm level but might be uneconomically large for the project and so require a compromise between the farm and project benefits. The actual flows taken would seldom be the maximum design limiting flow which should be appreciably larger than the average one to remove farm restraints, possibly
$1,300 \mathrm{~m}^{3} / \mathrm{h}$. "Do not limit the future by what is built now." Make evaluations to gain actual experience.

In a developing country where 1.0 ha ( 2.5 acre) might be an irrigation unit farm area and the duration remaining the same at $10 \mathrm{~h}$ being related to soil and method, the average flow rate would be about

$$
\begin{aligned}
0.125 \mathrm{~m} \times 1.0 \mathrm{ha} \times 10,000 / 10 \mathrm{~h} \\
=125 \mathrm{~m}^{3} / \mathrm{h} \\
=35.0 \mathrm{lps}(1.3 \mathrm{cfs}) \text { per } 1.0 \mathrm{ha}(2.5 \mathrm{acre}) \text { field }
\end{aligned}
$$

This average flow is too small a stream to be very efficient and a larger stream should be made available, soil intake rates and methods permitting. Two streams arranged for a half-day each but still covering two farms or one stream divided between two farms for two days may be practical for some soils. This might be arranged under the arranged demand schedule. Let the farmer operate the flexible system flexibly.

Project benefits are appreciable. For example, the Orange Cove Irrigation District, Calif., reduced its field crew by one-half (Chandler et al. 1990; Merriam et al. 1990).

System Costs.

\section{System Pipe Capacities}

System capacity needs to be at least doubled for a flexible daytime only operation relative to a $24 \mathrm{~h}$ or rotational system needs to be increased. The increased costs are invariably more than compensated for by on-farm tangible and intangible benefits such as: (1) reduced and more convenient labor; (2) increased yields; (3) more efficient irrigation and water conservation; (4) reduced potential drainage and salinity; and (5) reduced inter-farmer (top ender/low ender) conflicts.

If relative pipe costs were 1.00 for $200 \mathrm{~mm}$ diameter for one stream, 1.13 for $250 \mathrm{~mm}$ for two streams, 1.41 for $300 \mathrm{~mm}$ for three streams, and 1.78 for $350 \mathrm{~mm}$ for 4.5 streams, to double from a small stream for $24 \mathrm{~h}$ to daytime only would cost $13 \%$ more for pipe, with twice the flow rate. To make possible the use of two large daytime only streams with low congestion on a distributor using tapered size would increase distributor pipe cost about $45 \%$. Lateral costs would increase less, and the major project costs might decrease.

If the annual costs of just the distributor pipelines were as much as one-fourth of the project annual costs, the $45 \%$ increase to obtain an optimum flexible distribution would only be $(1 / 4$ $\times 45 \%$ ) about $11 \%$ of project cost, and the resulting increased water charges would be easily compensated by the many benefits. The lateral would be negligibly more (see Table 4) not needing to be increased in the upper portion.

\section{Flexible Operation Capacities}

To directly supply a single small pilot or demonstration area without a service area reservoir but using a downstream controlled lateral, the branch canal can function either with upstream or downstream control. The canal must provide through operation or in-canal storage for: The rejected overnight flow; for the lesser changes caused by on-farm irrigation operations such as initial and cutback furrows flows or early or late turn-on and turnoffs; different set sizes, etc. This is difficult on a project scale except for very large canals or with operational spillage but is practical for pilot or demonstration projects (Merriam 1991). 
Table 3. Relative Lateral Capacities with and without Midpoint Reservoir, Flexible Schedule, 80\% Congestion, Cover All 200 Farms in Eight Days out of 10 with up to 25 Streams of up to $40 \mathrm{lps}$ for Variable Durations (Daytime Only)

(a) Without reservoir (pipe size decreases with length)

\begin{tabular}{lc} 
Flow at canal $1000 \mathrm{lps}$ & Relative pipe diameter 119 \\
Flow at midpoint $500 \mathrm{lps}$ & Relative pipe diameter 91 \\
\hline
\end{tabular}

(b) With reservoir (pipe size decreases only in lower half, $24 \mathrm{~h}$ flow constant in constant size upper half)

\begin{tabular}{ll}
\hline Flow at canal $500 \mathrm{lps}$ & Relative pipe diameter 91 \\
Flow at midpoint $500 \mathrm{lps}$ & Relative pipe diameter 91 \\
\hline
\end{tabular}

For distributor deliveries of two streams, the upper reach should be longer than half lengths to allow for the probability that two streams would be needed in the lower half. Such need could be constrained by arrangement. It is more desirable to extend the double capacity of the upper part of the pipeline 0.6 to 0.7 of the length to provide better service with less congestion. Also, since the flow rate is to be arranged in the section is site specific and related to this specific area and not to a day of availability, it may vary from the unit farm stream size. The design flow rate may cautiously be reconsidered.

Where main or branch canals have inadequate capabilities to handle the major changes resulting from the flexible schedules, additional storage capacity must be developed. The service area reservoir is usually the most practical procedure. With such a mid-area reservoir the lateral above the reservoir can operate under upstream control. It may be on open or semiclosed pipeline, or a sloping (existing?) canal if offtakes have adequate head to function.

The lateral capacity in the upper half above the reservoir need only be a bit larger than the average $24 \mathrm{~h}$ flow rate. This is one of the benefits derived from having a service area reservoir. If the lateral were operated in downstream control mode, without storage the lateral must have more than twice full capacity to supply all the service area demands in the daytime (see Table 3).

\section{Pipe Capacity Design Illustrations}

\section{Flow Rate and Unit Farm Stream}

For illustration of reservoir and pipeline capacities, assume ET is $8.0 \mathrm{~mm} /$ day $(0.33 \mathrm{ipd})$ on a 200 ha area served by a lateral, and $60 \%$ application efficiency. Then for this illustration the daily volume (average) would be

\section{$0.008 \mathrm{~m} /$ per day $\times 200 \mathrm{ha} / 60 \%=2.67$ ha $\mathrm{m} /$ day}

and the application interval for a management allowed deficiency (MAD) (Merriam 1966) of 75-100 mm [a (f) of crop and soil] would range from

$$
\begin{aligned}
75 \mathrm{~mm} / 8.0 \mathrm{~mm} \text { per day } & =10 \text { days to } 100 \mathrm{~mm} / 8.0 \mathrm{~mm} \text { per day } \\
& =13 \text { days }
\end{aligned}
$$

The average $24 \mathrm{~h}$ continuous supply flow rate to the 200 ha service area at $60 \%$ application efficiency for a rotation schedule (100\% congestion) would be

$$
\begin{aligned}
2.67 \text { ha } \mathrm{m} \times 10,000 / 24 \mathrm{~h} & =1,110 \mathrm{~m}^{3} / \mathrm{h} \\
& =310 \mathrm{lps}(10.9 \mathrm{cfs}) \text { steady flow }
\end{aligned}
$$

For a $12 \mathrm{~h}$ delivery, the rate would be twice as great $(620 \mathrm{lps})$, and even larger for 10 or $9 \mathrm{~h}$ durations required by different soils, but the needed daily volume remains the same.

For a 1.0 ha farm for a $12 \mathrm{~h}$ set in a 10-day irrigation cycle, applying $80 \mathrm{~mm}$ at $60 \%$ efficiency $(133 \mathrm{~mm})$ the average flow rate for a farm turnout would be

$$
\begin{aligned}
& (80 \mathrm{~mm} / 60 \%)(1.0 \mathrm{ha} \times 10,000) /(12.0 \mathrm{~h} \times 3600 \mathrm{~s}) \\
& \quad=30.8 \mathrm{lps}(1.1 \mathrm{cfs})
\end{aligned}
$$

This average rate is too small to be practical. For $10 \mathrm{~h}$ or shorter sets and an increase for on-farm variations, the practical flow rate limit for the initial stream (unit farm stream) might be $45 \mathrm{lps}$ (1.6 cfs) (50\% greater), which could be cutback. For a 13-day cycle $(100 \mathrm{~mm})$ and a $12 \mathrm{~h}$ set, the average flow rate is $40 \mathrm{lps}$ so the design limit might better be $55 \mathrm{lps}$ (unit farm stream). This limiting figure is a key value and must be set with judgment as not all farmers will use it. With increased labor nighttime hours can be used, but should be avoided. "The engineer must learn to think like an educated farmer." Evaluation experience is very helpful. The actual soil intake rate and needed duration are critical.

Illustrating the use of the simple "basic stream" for practical on-farm use $(1.0$ basic stream for $1.0 \mathrm{~h}$ on 1.0 ha applies $1.0 \mathrm{~cm}$ ) an $80 \mathrm{~mm}$ soil moisture deficiency at $60 \%$ efficiency requires a $8.0 \mathrm{~cm} / 60 \%=13.3 \mathrm{~cm}$ irrigation. To apply this to $1.0 \mathrm{ha}$ in $12 \mathrm{~h}$ requires $13.3 \times 1.0 / 12.0=1.10$ basic stream $(30.8 \mathrm{lps})$.

\section{Number of Farms per Day}

In the United States the representative average number of 8.0 ha unit farms per day for a 10-day cycle in a 25 farms, 200 ha service area would be

(200 ha/8.0 ha)/10 days

$$
=2.5 \text { farms } / \text { day (not a real value }- \text { it is either } 2 \text { or } 3 \text { ) }
$$

and in a developing country with 1.0 ha unit farms

$$
\text { (200 ha/1.0 ha)/10 days }=20 \text { farms/day }
$$

The supply and conveyance capacity and the needed reservoir capacity to operate this area with a flexible schedule and acceptable congestion is related to probability and an economically acceptable congestion - the degree of assurance of delivering water on the date first requested under a limited rate arranged-demand schedule. For example, on the arranged date for up to the illustrated limiting flow rate of $45 \mathrm{lps}$ varied as desired for as long as needed on that day, what capacity will be needed? These limiting conditions must be determined with great care to not appreciably restrict on-farm operations.

For this illustration, in the USA the "average" of the 25 farms would be either two or three unit streams. With a flexible schedule four or one or even none might be arranged. With three streams used as a design limit to determine the "limiting" pipeline capacity rate, the congestion would be $25 / 3 \times 10=83 \%$, which is rather restrictive of the choice of day. It probably will not stress the crop. Flexibility involves both frequency (congestion) and volume of water. With four streams it would be $25 / 4 \times 10$ $=62 \%$ and could cover the 25 farms in six days out of a ten day cycle, which is adequate reserve. Consider using four streams. 
Table 4. Relative Lateral Capacities, Variable Frequency (Congestion), Rigid Rate and Duration, Pipe Diameter Reduces with Length

(a) $100 \%$ congestion, cover all 200 farms in rotation in ten days with 20 streams of $31 \mathrm{lps}$ fixed flow, $12 \mathrm{~h}$ duration (daytime only)

\begin{tabular}{lc}
\hline Flow at canal $620 \mathrm{lps}$ & Relative pipe diameter 100 \\
Flow at midpoint $310 \mathrm{lps}$ & Relative pipe diameter 77 \\
\hline
\end{tabular}

(b) $80 \%$ congestion, cover all 200 farms in eight days out of ten with up to 25 streams of $31 \mathrm{lps}$ fixed flow, $12 \mathrm{~h}$ duration (daytime only)

Flow at canal $775 \mathrm{lps} \quad$ Relative pipe diameter 108

Flow at midpoint $340 \mathrm{lps} \quad$ Relative pipe diameter 83

For a developing country with many small units to be covered in 10 days, a higher level of congestion would cause negligible problems with the 200 farms. An 80\% congestion level resulting in irrigating up to 25 farms per day might be questionably acceptable. With 1000 farms the usual daily request would approach nearer to the average (but a reserve for weather and holidays is still needed) and so $80 \%$ may be acceptable. In humid areas with frequent rainfall more reserve may be essential to provide for simultaneous startup requests.

With the United States example with only 25 unit area farms, it is very likely that on some days that one or four stream(s) would be requested (a wide range). However, with the developing country situation with 200 farms with an average 20 farms per day there would be low probability that 10 or 30 would request water on any day. The acceptable level of congestion affects the needed reservoir storage and system capacity. The canal turnout peak capacity for the United States example is either three or four streams of 250 lps average. The peaking capacity should be perhaps $30 \%$ greater so four $375 \mathrm{lps}$ streams $(1,500 \mathrm{lps})$ would be acceptable for flexibility. Allowing for the probability that not all four farms would simultaneously take peak flow, a flow of 1,300 lps could be acceptable, but would it really save much on meter charges over the 1,500 lps capacity? A pipe cost study would show very little difference in annual costs so use the larger one.

\section{Relative Flow Rates and Pipe Diameters}

For the developing country condition, an illustration for a rigid rotation schedule and also as a basis for comparison is presented in Table 4 for a lateral pipeline taking off from a canal to deliver water to distributor lines for the 2001.0 ha farms. This table shows (1) for $100 \%$ congestion (20 farms per day but for daytime only); and then (2) for $80 \%$ congestions (averaging 20 farms per day but allowing up to 25) in a ten day irrigation cycle, the flow rates and relative pipe diameters needed at the beginning and at the midpoint of a lateral for a rigid rate and duration schedule without a service area reservoir.

The $80 \%$ congestion allows some flexibility in frequency but not for rate and duration though that can be arranged. This is commonly done in the United States with $24 \mathrm{~h}$ durations. This restricted (rigid rate and duration) arranged schedule is not a good one but is simple for illustration purposes. Overnight unused flow will be absorbed in the canal or a reservoir or operation.

Pipe capacities and relative sizes shown in Table 4 for schedules with rigid rate and duration, show that to provide for $80 \%$ congestions (moderate flexibility in frequency), lateral capacity is increased from 620 to $775 \mathrm{lps}$, a $25 \%$ increase. Pipe diameter is increased from 100 to 108 , only an $8 \%$ increase. If pipe costs are about comparable to diameter, an $8-10 \%$ increase in lateral (not distribution) pipe costs may be anticipated. If lateral pipe costs alone are about $20 \%$ of total project costs, an appreciable degree of flexibility in frequency can be obtained for only about $2 \%$ increase in project costs and corresponding water charges.

In Table 3, a good flexible limited rate arranged-demand schedule with $80 \%$ congestion allowing moderate flexibility in frequency, with up to a $30 \%$ increase over average flow rate, and durations as needed to match soil intakes and farm conditions, is illustrated (1) without; and (2) with a mid-area service reservoir. Arranged scheduling will limit deliveries to only 25 farms on any one day even though more might be requested, or permit night time irrigation.

The illustration of a satisfactory flexible schedule of adequate frequency, rate and duration in Table 3, shows that without a service area reservoir, with all the flexibility supplied by the main canal for daytime only usage, that for the 60\% (620-1000 lps) increase in off-take capacity only a $19 \%$ increase in initial pipe diameter would be required.

However, by using a service reservoir, Table 3 shows that almost all of the project flow variables can be absorbed by the reservoir. This will also permit the main canal to have very steady flows and appreciably reduce its cost. This alternate, by using the upper portion of the service area lateral $24 \mathrm{~h}$ per day rather than $12 \mathrm{~h}$ as in Table 3, reduces the capacity to $500 \mathrm{lps}(50 \%)$ and the pipe diameter to $91 \%$ for its entire length in the upper half (some practical modifications are necessary).

These are the essential benefits of service area reservoirs. They make possible the many on-farm benefits from flexibility without appreciably changing the usual canal operations even with silt. This makes upgrading of many existing systems possible and greatly reduces canal operation problems, costs and operational spillage. The cost of the reservoir even with retaining some silt is compensated for by reduced pipe costs and the many on-farm benefits. "The farm and the project are one financial unit."

\section{Reservoir and Pipeline Capacity and Operation}

\section{Using the Project Supply and Storage Reservoir and Canal Storage}

Where a service area lateral pipeline (an automated elevated level-top canal may be cheaper on very nearly level ground) can be closely connected to the project supply reservoir (or equivalent), flexibility can be obtained by having adequate capacity in the lateral pipeline, or level-top canal, without a supplemental reservoir as in Table 3, but the supply canal will have large day to night and daily fluctuations. Such lateral capacity would need to be large enough in the upper initial reaches to supply all anticipated streams. From the introductory illustration in the United States (similar to Table 3) this would be four $375 \mathrm{lps}$ (1,500 lps) streams reducing to three and then two near the lower end and one in the last reach. It would be used essentially only in the daytime. It would utilize the existing in-canal storage capacity or canal operations so the fluctuating off-takes would be satisfied. If a closed or semiclosed pipeline were used, it would be a fully automated system, as used on the Orange Cove Irrigation District (Chandler et al. 1990) with appreciable but acceptable canal fluctuations.

\section{Using a Service Area Reservoir}

If the 200 ha United States illustration was not located near the storage reservoir but did take off from a main or branch canal on 
which it was desired to maintain a nearly stable rate, a service area reservoir of 2 or 3 ha m or more capacity would be located near the center of the service area as presented in Table 3. The conceptual illustration of operation under a flexible schedule with a rigid $12 \mathrm{~h}$ daytime only supply shows the value of a service area reservoir.

With the midpoint location, the stream size in the upper portion would average $11 / 4$ streams full flow rate needed for a $24 \mathrm{~h}$ run desired to stabilize canal flow rather than the full $21 / 2$ stream needed for $12 \mathrm{~h}$. The overnight unused flow at this same rate then flows into the service area reservoir to provide the flow needed the next day in the lower area. In practice the probability is that in the United States example, three and occasionally four $375 \mathrm{lps}(1,500 \mathrm{lps})$ streams (daytime only) could be needed at times in the total area. This would increase the required practical design capacity to two streams rather than the $11 / 4$ average flow rate. It would be limited by arrangement to only two each in the upper and lower portions. An operation program should be made for maximum conditions. With many outlets for the developing country illustration, the incremental upper half increase would be less.

Additionally, since the variable farm turnout flow rates in practice are usually taken for less than $12 \mathrm{~h}$, the actual rate must be larger than the average $12 \mathrm{~h}$ flow rate illustrated, though the needed volume remains about the same. This practical condition requires that a larger than average flow be planned from the canal during the daytime period to satisfy the actual upper portion farm needs which are taken for less than $12 \mathrm{~h}$, plus some operational reserve. For the few hours practical increment of time difference, this larger flow will bypass into the service area reservoir with its large operational storage. For the rest of the $24 \mathrm{~h}$, the needed smaller overnight flow, which is not reduced by off-takes in the upper portion, may be controlled by a valve on a semiclosed pipeline system where it outlets into the reservoir. The use of the arranged schedule permits these two daily flow rates to be anticipated and taken from the canal and the reservoir absorbs the inevitable small mismatches. If the lower area is about $55 \%$ of the total area rather than half, the day and night flows can be more nearly equal with adjustments made the following day. If the reservoir is appreciably larger, only one morning flow adjustment may be needed.

If the service area lateral is a closed or semiclosed pipeline, operations can be automated. If the upper area line is closed at the outlet into the reservoir during the day, or a moderate outflow is set and the line has adequate capacity, upper area farm off-takes can be made as desired and the inflow into the pipeline from the canal equates exactly and automatically. The canal supplies this fluctuation from planned scheduled flow or in-canal storage. With pipeline canal off-takes, a constant head at the canal is not essential and in-canal storage fluctuations are acceptable as done at the Orange Cove, Id. At night all flow would go into the reservoir at the desired rate to balance canal conditions with a float valve preventing the reservoir from overflowing. It is noted that flow changes into the reservoir can be made at the outlet end of a semiclosed or closed pipeline. If open pipelines or canals are used in the upper portion, controls are set at the canal and flows are stable with fluctuations absorbed in the reservoir.

Irrigation below the service area reservoir starts with a nearly full reservoir. A little space is left for mismatches and variable startup times from the reservoir the next morning. Off-takes through closed or semiclosed distributor pipelines are taken by the farmers as desired and about as scheduled. They are automatically supplied from the reservoir storage. Most operations will require only morning and evening reservoir adjustments. All farm turnout adjustments are made by the farmer at his valve with the reservoir absorbing all modifications in the lower area. This technique may be the simplest to upgrade existing systems as very little change is needed in the canal system and the lateral above the reservoir. It may be done in small units as each service area is independent.

It is to be emphasized that while construction of service area reservoirs in addition to major storage reservoirs, has been common knowledge for a long time, their use as a tool to facilitate upgraded on-farm use of water and labor and resulting improved on-farm management has not. The resulting flexibility in supply in conjunction with an adequately large pipeline distribution system (Merriam 1987c) can accomplish the basic on-farm objective of overcoming common management restrictions. An educated farmer can then perform at the optimum level (Merriam 1991; Merriam 1999; Merriam and Freeman 2002).

\section{Silt Load}

In locations where there is a silt problem, the flexible supply technique leaves the supply system-main, branch, and lateral canals-operating at a steady flow regime condition, which transports the silt.

In the typical flexible supply layout with the service area reservoir near the center of the service area, the portion of the service area above the reservoir is essentially served directly through the pipeline distribution system conveying the silt-laden water directly to the field. The nighttime flow essentially delivered through the service area reservoir for daytime usage in the lower service area will drop most of its silt, which must ultimately be removed mechanically or hydraulically with a small portable dredge and desirably spread on the lower farm fields.

\section{Coordinated Return Flow System}

The moving water surface irrigation methods involve runoff or blocked ends. Furrows have a higher distribution uniformity (DU) when using larger initial streams but with increased runoff. Cutback streams reduce runoff and return flow systems eliminate it. Both can be facilitated with flexible supply systems, which can result in high application efficiencies (AE).

With the flexible supply system, the usual large return flow runoff storage reservoir at the lower end of a field and the large pump can simply and economically be replaced. A smaller cycling pump taking water from a small sump can return flow directly to the farm system at a point between the project farm supply turnout valve, which is operated fully open or closed, and the field control gate. The return flow surge at this point must be considered. The return flow is reapplied to the field from which it runs off. The supply flow is automatically reduced by the return flow to a net combined flow that just matches the soil intake rate.

\section{Pipeline Project Supply to the Farm}

If the project supply system is a pipeline, the farm turnout gate, which is operated wide open or closed, releases flow through a Harris float valve into a farm standpipe in which the downstream water level is maintained nearly constant by the Harris float valve on the project supply regardless of a variable farm outtake rate or supply pressure or rate variation. The outlet gate from the stand- 
pipe to the field distribution system is operated to control flow to the usual sloping field head ditch at any desired easily varied rate.

If the head ditch function is done by a pipeline, the farm outlet gate is operated wide open sand control is at the outlet in the field - gated pipe, alfalfa valves, etc., stabilized by the Harris float valve. Large streams can be set in small sequential subsets for convenience of labor.

If the head ditch function is done by a level-top ditch stabilized by a Neyrtec or Waterman downstream float control gate, it can function as flexibly as a pipeline distributor. If the ditch float gate is omitted, flows must be modified manually as subsets are made. In-ditch storage having small changing head variations on outlets make this practical-inflow matches taken outflow at some level.

With these systems, cutbacks are made for the entire set at the one gate in the field supply standpipe. The farm outtake variations are absorbed by the project flexible supply system. Field outlet cutbacks will not be uniform and may need re-regulation especially for pipeline systems. Cutbacks do not save water but do save power. They are not essential. The larger initial furrow stream and fast advance ratio (AR) provide uniformity and do save water (Merriam 1988).

\section{Canal Project Supply to the Farm}

In the unusual condition where farm outtakes are from flexible project laterals which are level-top canals or sloping canals with flexibility obtained by operational spillage over constant level gates or long-crested weirs, farm turnout to level-top or sloping field head ditches can "float" on the project supply lateral canal at a constant level regardless of outtake rates. For the return flow systems to a level-top head ditch, the return may be made to any place and the supply flow will be slowly reduced to match. The return to a sloping head ditch must be made between the project turnout and the farm control gate as for the pipeline supply procedure. The operation of the head ditch is as described above and the return flow surge must be considered.

Summarizing, flexible supply systems facilitate the installation of runoff return flow systems where required or desired. The elimination of low side storage reservoirs and the use of small cycling return flow pumps is possible. Such systems facilitate the use of proper sized initial streams, reduce labor and the needed precision of flow sets, and economically eliminate runoff allowing moving water surface irrigation methods to have high application efficiencies.

The equivalent program for all cases can be obtained from individual on-farm reservoirs as the flexible source (Merriam 1987c).

\section{Conclusions}

Flexible on-farm management of an irrigation water supply is essential for the farm manager to obtain optimum use of land, water, crops, weather, and labor resources. Irrigation must be coordinated with other aspects of the farming operation. Supply restraints on the control of flexibility of frequency, rate and duration must be economically minimized. Daytime only irrigation is nearly essential. A partially flexible system is of limited value.

For the mechanical pressurized irrigation methods, rate is selected and remains fixed. Management controls are through variations of frequency and duration. For surface methods, rate must also be varied to correspond to variable soil intake conditions.
The large capital-intensive main water supply portion of a project system operates most effectively near capacity and continuously, but almost all on-farm distribution systems operate intermittently. At field levels the irrigation intervals for surface methods are large, typically one to several weeks of nonuse. To reconcile these extremes requires storage. Such storage is best located between the secondary and tertiary systems as close to the point of application as practical to permit the steady flow supply system area to be as large as is economical. This favors the use of centrally located service area reservoirs and requires the use of pipelines to permit local control while allowing supply canal operations to be upstream controlled. Essential items are farmer and operator education, Water User Associations, limited rate arranged-demand schedule, and adequate post-construction guidance and funding. The studies made by the U.S. Liaison and Coordination Unit (1992) state that "an underground pipeline system should take the place of open channel lined or unlined, for the delivery system in the command, as this alternative allows the farmer to remit water in the field free from transit losses, and the O\&M problems, and last but not least involves practically half the cost of the normal open channel system - and that it takes less than half the time to complete job."

\section{Bibliography}

The reports or papers are obtainable upon request to the Fund For Furthering Flexible Irrigation c/o Irrigation Training and Research Center, Calif. Polytechnic State Univ., San Luis Obispo, Calif. 93407 〈www.4FI.org〉.

Chandler, J. C., Moss, R. M., and Merriam, J. L. (1990). “Automated low pressure pipe for flexible deliveries: Orange Cove Irrigation District, Calif." Symp. Proc., R4, XIV Int. Congress, ICID, Rio de Janeiro, Brazil.

Cross, P. R. (2000). "Benefits of a flexible irrigation water supply." J. Irrig. and Drain. Engrg., ASCE, 126(5) 275-278.

Davids, G., and Merriam, J. L. (1990). "Sri Lanka upgrades social, agricultural, and economic conditions with a demand irrigation schedule." Question 42, R1 14th Congress, Int. Commission on Irrigation and Drainage, Rio de Janeiro, Brazil.

Freeman, B. J., Merriam, J. L., and Joshi S. K. (2002). "Lessons learned from the gadigaltar flexible irrigation pilot project: Madhya Pradesh, India." ICID 18th Intl. Congress, Trans. Question 50, Poster Paper 4.03, Montreal.

Merriam, J. L. (1985). "Demand irrigation schedule concrete pipelines project.” Final Rep., Mahaweli Development Board, Sri Lanka.

Merriam, J. L. (1990). "Gadigaltar tank irrigation pilot project." Project Rep., Dept. of Water Resources, Bhopal, Madhya Pradesh, India.

Merriam, J. L. (1991). "Flexible Irrigation supply pilot projects. Part I: Principles; Part II: Sri Lanka, Pakistan, India, and Egypt." ASCE Irrig. and Drain., Div. Proc., Honolulu.

Merriam, J. L. (1998). "Installation of a flexible pipeline irrigation system in Egypt." ASCE, Proc., Water Res. Engrg., Vol. 2. Memphis, Tenn.

Merriam, J. L., Chandler, J. C., and Moss, R. M. (1990). “Upgrading the Orange Cove Irrigation District's water distributions system." ASCE Irrig. and Drain. Engrg., Div. Proc., Durango, Colo.

Merriam, J. L., and Davids, G. (1995). "Case history of irrigation water conservation: Demand irrigation schedule saves water 
on pilot project. Sri Lanka 1981-1985." USCID Seminar

Proc., Sacramento, Calif.

\section{References}

ASAE Standards. (1989). "Design and installation of non-reinforced concrete irrigation pipeline systems." ASAE S 261, St. Joseph, Mich.

ASCE. (1984). "Recommended irrigation schedule terminology." Conf. Proc. ASCE Irrig. and Drain. Div., R. Walker and Ch. Flagstaff, eds., On-Farm Irrigation Committee, Ariz., 219-221.

Chandler, J. C., Moss, R. M., and Merriam, J. L. (1990). “Automated low pressure pipe for flexible deliveries: Orange Cove irrigation district, Calif." Symp. Proc., R4, 14th Int. Congress, ICID, Rio de Janeiro, Brazil.

Clemmens, A. J. (1987). "Delivery system schedules and required capacities." Symp. Proc., Planning, Operation, Rehabilitation, and Automation of Irrigation Delivery Systems, D. D. Zimbelman, ed., ASCE Irrig. and Drain. Div., Portland, Ore., 18-34.

Goussard, J. (1987). "NEYRTEC automatic equipment for irrigation canals." Symp. Proc., Planning, Operation, Rehabilitation, and Automation of Irrigation Water Delivery System. D. D. Zimbelman, ed., ASCE Irrig. and Drain. Div., Portland, Ore., 121-132.

Merriam, J. L. (1966). "A management control concept for determining the economical depth and frequency of irrigation." Trans. ASAE, 9(4), 492-498.

Merriam, J. L. (1978). "Border-strip irrigation design-practical approach from a theoretical basis." ASAE Summer Meeting, Logan, Utah, Rep. No. 78-2008.

Merriam, J. L. (1987a). "Pipelines for flexible deliveries." Symposium Proceedings. Planning, Operation, Rehabilitation, and Automation of Irrigation Water Delivery Systems, D. D. Zimbelman, ed., ASCE Irrig. and Drain. Div., Portland, Ore., 208-214.
Merriam, J. L. (1987b). "Design of semiclosed pipeline systems.” Symp. Proc., Planning, Operation, Rehabilitation, and Automation of Irrigation Water Delivery Systems, D. D. Zimbelman, ed., ASCE Irrig. and Drain. Div., Portland, Ore., 224-236.

Merriam, J. L. (1987c). "Reservoirs help on-farm operation and automation." Conf. Proc., Irrigation Systems for the 21st Century, ASCE Irrig. and Drain. Div., Portland, Ore., 325-335.

Merriam, J. L. (1988). "Simple furrow advance ratio evaluation technique for upgrading management." Conf. Proc., Planning Now for Irrigation and Drainage in the 21st Century, ASCE Irrig. and Drain. Div., Lincoln, Neb., 106-115.

Merriam, J. L. (1991). "Flexible supply schedule missing link for effective surface irrigation and automation." ASCE I\&D Div. Specialty Conf. Proc., Honolulu, 764-772.

Merriam, J. L. (1999). "Retitling surface irrigation for clarity." ASAE Intl. Meeting, Toronto, Canada, Rep. No. 99-2093.

Merriam, J. L., Chandler, J. C., and Moss, R. M. (1990). "Upgrading of the Orange Cove irrigation district water distribution system." Specialty Conf. Proc., ASCE Irrig. and Drain. Div., Durango, Col.

Merriam, J. L., and Clemmens, A. J. (1985). "Time rated infiltrated depth families.” I\&D Div. Specialty Conf. Proc., Development and Management Aspects of Irrigation and Drainage Systems, ASCE, San Antonio, Tex., 67-74.

Merriam, J. L., and Freeman, B. J. (2002). "Irrigation water supplies to not inhibit improved water management." ICID 18th Intl. Congress, Montreal, Trans. Question 50, Rep. No. R3.13.

Styles, S. W. (1997). "Alleviation of surface and subsurface drainage problems by flexible delivery schedules." 27th Congress Proc., IAHR/ ASCE Water Res. Engrg. Div. Managing Water: Coping with Scarcity and Abundance, San Francisco, 717-722.

USAID Liasion and Coordination Unit. (1992). Tech. series no. 15, Dept. of Water Resources, Bhopal Government of Madhya Pradesh, India.

Van Bentum, R., and Smout, I. (1994). Buried pipelines for aurface irrigation, Water Engineering Development Center, Loughborough Univ. of Technology, Leicestershire, U.K. 